\title{
A revista Leitura: Teoria \& Prática - momentos no tempo
}

\section{The periodical Leitura: Teoria \& Prática - moments in time}

https://doi.org/10.34112/2317-0972a2017V35n70p13-32

\author{
Lilian Lopes Martin da Silva ${ }^{1}$ \\ Ezequiel Theodoro da Silva ${ }^{2}$ \\ LuCiane Moreira De Oliveira ${ }^{3}$
}

Resumo: Por ocasião da publicação do número 70 da revista Leitura: Teoria \& Prática, procuramos pontuar momentos significativos do itinerário da revista ao longo de seus 35 anos. Sua criação e publicação correspondem a uma das ações da Associação de Leitura do Brasil que, como os Congressos de Leitura (COLEs), se consolidou nacionalmente, por sua permanência, regularidade e qualidade, transformando-se em sua mais importante publicação. Em seu percurso, a revista passou por mudanças, que serão apontadas nesse relato, não abandonando seu objetivo inicialmente concebido: o de converter-se em espaço de debate e de troca de ideias entre interessados na temática da leitura. É o único periódico especializado nesse tema. Para a construção deste relato, utilizamos a própria revista como fonte e outros documentos pertinentes ao assunto.

Palavras-Chave: Revista Leitura: Teoria \& Prática; revista especializada; leitura; memória.

ABStRACT: On the occasion of the publication of the issue 70 of the journal Leitura: Teoria \& Prática, we have scored significant moments of the itinerary of the periodical over its 34 years. Its creation and printing correspond to one of the actions proposed by the Brazilian Reading Association, which, just like the Reading Conferences (COLEs), has sustained

1. Universidade Estadual de Campinas, Campinas, SP, Brasil.

2. Universidade Alto Vale do Rio do Peixe, Caçador, SC, Brasil.

3. Universidade Estadual de Campinas, Campinas, SP, Brasil. 
national references, for its permanence, regularity and quality, becoming its most important publication. Throughout these years, the journal underwent changes, which will be pointed out in this report, without abandoning its initially conceived goal, that is, to become a means for debate and exchange of ideas for those interested in the subject of reading. It is the only periodical specialized in this subject. For the construction of this report, we have used the publications themselves as a source, as well as other relevant documents to the subject.

KEYWORDS: Journal Reading: Theory \& Practice; specialized publication; reading; memory.

O relato por nós construído e aqui apresentado é apenas um dos possíveis. Nem mais e nem menos que qualquer outro. Nem melhor nem pior. Fruto de escolhas, seleções, desejos, sentimentos e principalmente do lugar que ocupamos nessa história. Estamos há muito tempo atuando na revista Leitura: Teoria é Prática (LTP). Por vezes mais intensamente, em outras, com um pouco mais de distanciamento. Seja em sua produção, revisão, avaliação de textos como parecerista, em sua distribuição aos sócios, seu gerenciamento financeiro, sua comercialização, como leitores, como autores...

No intuito de amenizar aspectos tão subjetivos, recorremos à própria coleção da revista, tomando-a como objeto oferecido a nossa leitura, pensando que em seus muitos números poderíamos encontrar as marcas que apontassem para sua história, em seus diferentes momentos e modos de fazer.

Não exploramos os textos por ela veiculados ao longo do tempo. Um universo discursivo capaz de, nas particularidades e diferenças entre os textos, dizer uma história das discussões sobre a leitura, a cultura, o livro e a educação nos últimos trinta e cinco anos. Ao contrário, exploramos editoriais, fichas técnicas, projetos gráficos, enfim, elementos que também sinalizam para os sentidos atribuídos à revista por seus produtores, seus modos de fazer e suas práticas, como para seu entorno, ou seja, a situação histórica, política e cultural no qual a Revista se enraizava a cada momento.

Nossa intenção é registrar, numa espécie de linha do tempo, o percurso da revista... Pontuar momentos no interior desse movimento de diferenças que se sucedem no tempo, resultantes de um conjunto vigoroso de reflexões na direção de fazer da LTP um periódico dos seus tempos.

O Informativo $A L B$, de abril de 1983, dá notícia aos associados da Associação de Leitura do Brasil (ALB) da edição número zero da revista Leitura: Teoria \& 
Prática. O periódico viera a público em janeiro daquele ano, publicado pela Editora Mercado Aberto, da cidade de Porto Alegre no Rio Grande do Sul.

O Comitê Provisório (sic) ficou com a tarefa de criar e editar o veículo de comunicação da ALB. Travamos diversas discussões a respeito da estrutura da revista, analisamos o formato e diagramação de outras revistas especializadas, verificamos vantagens e desvantagens de diferentes editoras, consultamos professores de $1^{\circ}$ e $2^{\circ}$ graus sobre $o$ título pensado para a revista, etc... Decidimos publicar Leitura: Teoria e Prática pela Editora Mercado Aberto, de Porto Alegre - uma editora pequena, meio deslocada do centro, mas oferecendo as vantagens que procurávamos e com um bom sistema de distribuição em nível nacional. ${ }^{4}$

A revista era a materialização de um dos compromissos assumidos pela diretoria provisória da ALB, fundada em novembro de 1981 . Com isso, a ALB cumpria o disposto no artigo terceiro, item $C$ de seu estatuto de 1982, apresentado na íntegra no número zero da LTP: "a publicação de uma revista semestral de leitura, organizada a partir da constituição da Equipe Editorial da ALB, decidida pela Diretoria.” (LTP $\mathrm{n}^{\circ} \mathrm{o}, 1982$, p. 43).

Desse momento inaugural até hoje, a revista percorreu 35 anos. Manteve, com raras exceções, sua regularidade e periodicidade. Não é pouco. Todos nós sabemos como é difícil manter um periódico em dia e por tanto tempo. Nesse percurso, a LTP vivenciou muitas dificuldades em seu processo de produção e passou por variadas mudanças: de formato, diagramação, conteúdo, estrutura, funcionamento, equipe de produção, editora... Ampliou seu escopo, dialogou com conjunturas sociais diferentes, com particularidades e ênfases das 19 diretorias da ALB, ajustando-se a elas. Entretanto, a revista não alterou os objetivos principais com os quais veio à público em 1983, que são explicitados no editorial de seu número zero:

LEITURA: TEORIA E PRÁTICA (...) nasce com o propósito principal de servir como veículo para a comunicação e o intercâmbio entre aqueles que se preocupam com os

4. Informativo ALB, $n^{\circ}$ 1, setembro de 1982 apud TAKAMATSU, S. M (2017, p. 195). Conforme SILVA, L. L. M. E OLIVEIRA, L. M. (2014, p. 17 e 21) o Comitê Provisório da ALB era formado por: Ezequiel T. da Silva; Lilian L. Martin; Olga Molina; Marli Pinto Ancassuerd; Leonídio B. da Silva; Marina B. T. Mendes; Mary Fátima de L. Mendonça; Raquel M. de A. Prado; Regina Celi de Souza. Esse Comitê deu origem à $1^{\text {a }}$ Diretoria Provisória (1981-1983). 
problemas da leitura em nosso país. (...) Pretende ser um fórum semestral de debates, reservando aos seus leitores espaço para relatar suas experiências teóricas e práticas. (LTP, nº 0 , 1982, Editorial).

A primeira Equipe Editorial da LTP foi formada por integrantes da Diretoria Provisória da ALB. Ela responsabilizava-se pela captação, avaliação e seleção dos textos; composição da revista; produção de editorial e, posteriormente, de sua distribuição aos sócios. A revista organizou-se durante muitos anos, em sessões bem demarcadas e delineadas que apresentavam artigos/estudos, pesquisas concluídas ou em andamento, relatos de experiência, entrevistas, opinião, resenha, lançamento, atualização, divulgação, além de um espaço, a partir do no ${ }^{\circ}$, para textos de ficção, como contos, poesia etc.

Para SILVA (1998, p. 155) "Pode-se perceber aí uma mudança importante no nosso modo de conceber o processo de formação do leitor-professor. Não apenas pela reflexão sobre a leitura, mas pelo exercício da leitura".

Seu formato, um quadrado de $23 \times 23 \mathrm{~cm}$, inspirado num periódico contemporâneo, a Revista da Associação Nacional de Educação - ANDE, que a diferenciava dos livros e das revistas convencionais, além de permitir uma diagramação do texto em uma, duas ou três colunas, combinando-o com outras linguagens, e deixando a página mais arejada. Quase todas as fotos e ilustrações constantes dos primeiros números da revista eram, conforme lembra o Prof. Ezequiel T. da Silva, obtidas pela ALB junto à Câmara Brasileira de Livros, o que representava uma dificuldade, pois havia a questão dos direitos autorais em uma época em que as imagens não eram tão disponíveis quanto hoje em dia.

Segundo Silva (1998, p. 149):

[...] esse formato ajudava no desejo de descolamento do veículo do mundo eminentemente acadêmico, identificado a uma minoria elitizada de profissionais, tão distante dos professores que buscávamos encontrar, com quem queríamos conversar. $\mathrm{O}$ apagamento ou a simples redução das marcas do acadêmico tanto nos textos quanto nos seus suportes materiais era no nosso entendimento um movimento necessário para o êxito que esperávamos obter com a publicação. 
Uma outra estratégia utilizada em seus 13 primeiros números, visando facilitar não só a aceitação do periódico pelos leitores especialmente pretendidos, como sua compreensão - os professores - foi a inclusão de comentários, sínteses ou conselhos para a leitura, elaborados pelo conselho editorial. Esses pequenos "adiantamentos" vinham logo abaixo do título de cada texto "Como a jogar luz sobre a sombra compacta do texto, para iluminar os aspectos sobre os quais este [o leitor] deveria por atenção" (SILVA, 1998, p. 152).

LTP configurava-se, assim, como um lugar de formação dos leitores, "de mobilização e de consolidação de uma comunidade crítica e coletiva em torno de um objeto específico de investigação: a leitura" (LTP, no 41, 2003, Editorial).

As duas primeiras publicações da LTP reuniram contribuições de conferencistas e palestrantes dos Congressos de Leitura do Brasil já realizados, para depois ir incorporando as colaborações enviadas ou encomendadas, muitas delas relatos de experiências. ${ }^{5} \mathrm{O}$ projeto gráfico, composição e revisão, bem como a impressão desse número e de todos os 41 seguintes (até 2003) ficaria a cargo da editora Mercado Aberto, de Porto Alegre/RS.

Nesse conjunto é possível identificar algumas características permanentes: layout de capa, com variação apenas nas imagens enquadradas ao centro; edição em forma de brochura, presença de vinhetas, chamadas, nome das seções, ilustrações e epígrafes distribuídas pelo miolo. $\mathrm{O}$ número de páginas varia conforme o tempo de vida da revista, ficando entre 50 e 80 páginas. Tudo de modo a habituar o leitor pretendido ao periódico... "Os leitores inscritos nos primeiros números da revista parecem ser, antes de tudo, leitores que precisam ser tomados pelas mãos, a quem se precisa guiar." (SILVA, 1998, p. 153) ${ }^{6}$.

5. "A proposta inicial para a revista, discutida pela diretoria provisória, veio da professora Lilian L. Martin da Silva, docente da Faculdade de Educação da Unicamp e membro da diretoria da ALB. O esboço trazia alguns dos conteúdos para a edição da revista projetando um editorial, elaborado pela diretoria provisória da ALB e que ressaltasse a linha editorial da publicação; artigos específicos que resgatassem os conteúdos das mesas-redondas, comunicações e/ou conferências dos COLEs; artigo sobre uma pesquisa já finalizada em nível de pós-graduação; artigo sobre pesquisa em andamento no nível de pós-graduação; resenha de livro e informes gerais. Dessa discussão em reunião da diretoria, resultou a aprovação do esboço para as primeiras duas edições da revista LTP...” (TAKAMATSU, 2017, p. 194).

6. A década de 1980 viu a questão da formação de leitores entrar na pauta das políticas públicas... Assim, foi criado pela FAE - Fundação de Assistência ao Estudante, órgão ligado ao MEC, o Programa Nacional Sala de Leitura - PNSL, que se realizou entre os anos de 1984 a 1987. Seu trabalho era compor, enviar acervos e repassar recursos para ambientar as salas de leitura. Foram distribuídos livros de literatura para os alunos e periódicos para alunos e professores. Era um programa realizado em parceria com as Secretarias Estaduais de Educação e com universidades responsáveis pela capacitação dos professores. Confira em: <http://portal.mec.gov.br/ 

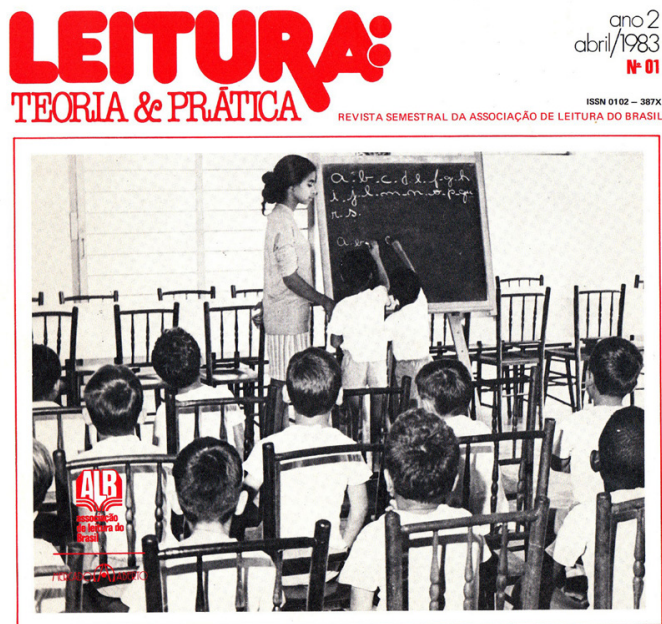

\section{A PRODUGÃO}

DA IFITURA F

SUAS CONDIGOES

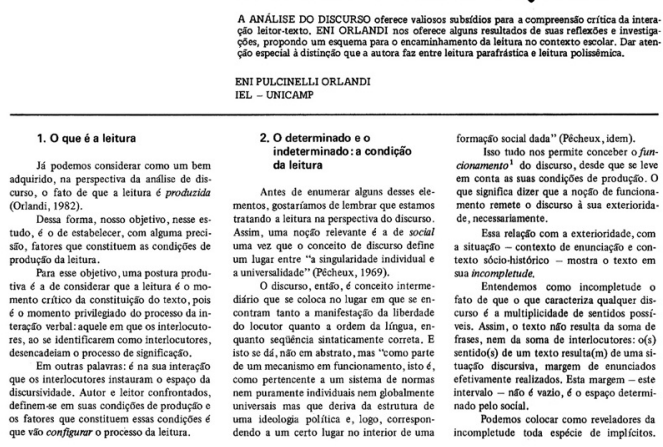

Figuras o1 e 02: Revista Leitura: Teoria \& Prática, no 1, 1988. Capa e p. 20

dmdocuments/pnbe.pdf $>$. Ao investigar as capas das revistas disponíveis, é possível concluir que, durante um período, a LTP fez parte desse acervo. Não é possível dizer em que extensão, nem quando exatamente. Seria necessário pesquisar os documentos do arquivo administrativo da entidade, mas foi possível constatar que, em algumas capas, ao lado do logo da ALB, há o selo da FAE/Salas de Leitura, além da informação referente ao ano e o número da reimpressão, que estão presentes nas fichas técnicas de cada revista. 
Em 1987, na LTP no 10, a Equipe Editorial passou a ser denominada Conselho Editorial e ampliou-se, integrando professores da escola básica. ${ }^{7}$ Posteriormente, em 1991, na LTP no ${ }^{17}$, criou-se uma coordenação para esse Conselho, também denominada, por vezes, presidência. ${ }^{8}$ Nesse número da revista, para comemorar os 10 anos de vida da ALB, a LTP publicou um encarte especial de 20 páginas, reunindo contos e poemas. ${ }^{9}$ Em 1994, o ${ }^{\circ} 24$ da revista apresenta pela primeira vez um Conselho Editorial Externo, composto de "profissionais de reconhecido mérito, atuando em diferentes regiões do país". Será um conselho externo à diretoria, à cidade de Campinas e à Unicamp, local da sede da ALB. O conselho anterior passou a ser um Conselho Executivo, uma inovação que veio responder aos anseios de reformulação da revista expressos pela diretoria, que desejava vê-la refletindo sobre a prática da leitura para além do ambiente escolar e institucional:

A nova diretoria da Associação de Leitura do Brasil, eleita durante o $9^{\circ}$ Cole para o biênio 94/95, tem como um de seus projetos reformular a revista Leitura: teoria \&, prática buscando aprimorar ainda mais a qualidade desta publicação e consolidar a sua importância na divulgação de ideias e no debate intelectual de que vem participando ao longo dos últimos doze anos. Temos muitos planos para o setor de publicações, buscando dar um salto de qualidade em nossa revista. (LTP, nº 23, 1994, Editorial).

Duas novas seções são criadas: Leituras do Mundo e Representações de Leitura. A primeira virá a ser o embrião da seção destinada às publicações de artigos internacionais, surgida mais à frente. A segunda vai ocupar-se da reprodução de fotos, pinturas ou charges, que tematizem a leitura. O número seguinte da LTP $\left(\mathrm{n}^{\circ} 24\right.$,

7. Foram integrantes desse primeiro Conselho Editorial: Ana Luiza Smolka; Clorinda Lanfranchi; João Wanderely Geraldi; Maria Laura Mayrink-Sabinson; Maria do Rosário Mortatti; Milton José de Almeida; Raquel S. Fiad, além de Hilário Fracalanza; Lilian L. Martin da Silva; Ezequiel T. da Silva e Olga Molina.

8. A primeira Coordenação foi de Lilian L. M. Silva. Essa é uma função que permanece até os dias de hoje, sendo assumida por diferentes pessoas, em geral, ligadas às diretorias. Já assumiram esta função: Guilherme do Val Toledo; Gabriela Fiorin Rigotti; Norma S. de A. Ferreira; Márcia Abreu; Maria José Nóbrega; Wilton José Marques; Davina Marques.

9. Um encarte produzido para acolher a expressão literária de autores novos: Ana Cândida Costa, Paulo Sampaio, Vicente Cechelero, Alípio Correia de França Neto, José Augusto Carvalho, Milton José de Almeida, Cláudia Araújo Ortiz..."gente como a gente que colabora com a ALB...” (LTP nº 17, 1991, Editorial). 
1994) já materializa esses desejos trazendo a composição do Conselho e a seção Representações de Leitura ${ }^{10}$. É ainda nesse período que as capas passam a ter um acabamento em papel plastificado, mas mantendo o layout das anteriores, exceção das imagens enquadradas ao centro nas quais serão largamente utilizadas representações de leitores. Em 1996, a LTP no 28 esclarece a mudança de ênfase que marca os números desse ciclo iniciado dois anos antes:

Passados 15 anos da fundação da Associação de Leitura do Brasil, 19 anos de COLE e 15 anos da revista Leitura: Teoria \& Prática, (...) a questão que se coloca, então, não é mais de como divulgar a leitura [refere-se ao fato de LTP ter se constituído como importante veículo para a expressão de vários segmentos sociais, especialmente os professores], mas sim de como garantir o acesso efetivo da maioria excluída à cultura e à educação. Neste sentido, Leitura: Teoria \& Prática, deve caracterizar-se como um espaço privilegiado de análise e crítica das práticas sociais de leitura, muito mais do que a divulgação de metodologias e técnicas de ensino.

Esse ciclo da LTP vai do número 23, de 1993 até o número 41, de 2003, cujo editorial traz o título "O editorial pergunta: quem são os leitores da revista Leitura: Teoria \& Prática?”. Com essas palavras, Silva e Prado (2003) registram as decisões do Conselho Editorial e buscam compreender o percurso da revista até aquele momento:

[...] a linha editorial anuncia a busca por maior penetração e representatividade da revista, com a participação de intelectuais de reconhecido mérito e de diferentes regiões do país: a amplificação da discussão sobre leitura não exclusiva ou prioritariamente voltada para a instituição escolar; o reconhecimento de que práticas de leitura e de escrita ocorrem em espaços diversos, numa multiplicidade de materiais escritos com seus suportes de textos e inúmeras combinações e estratégias [...]. Nesta nova proposição e conjuntura, a revista parece voltar-se para um leitor inscrito num mundo cultural cada vez mais alargado e complexo [...].

10. São integrantes desse primeiro Conselho Editorial Externo: Elias José, Fábio Lucas, Francisca N. F. Borges, Haquira Osakabe, José Paulo Paes, Lígia Chiapini, Lívia Suassuna, Magda Soares, Maria Bernadete Abaurre, Marisa Lajolo, Nilma Gonçalves Lacerda, Regina Zilberman, Sonia Kramer. Na seção Representações de Leitura, a expressão xilográfica. 

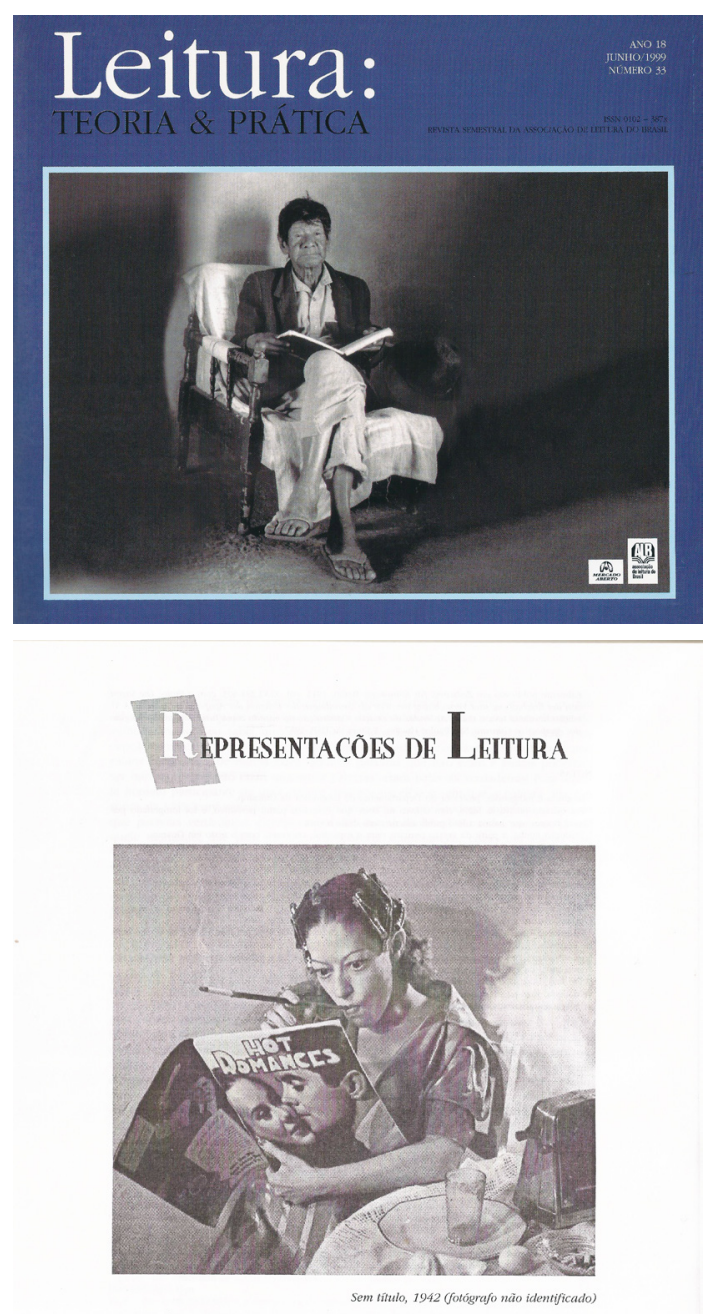

Figuras 03 e 04: Revista Leitura: Teoria \& Prática, no 33, 1999. Capa e p. 44

III

O número 41 da LTP, que sairia em setembro de 2003, veio a público em junho de 2004 acompanhado de um pedido de desculpas da diretoria porque depois de 21 anos sendo publicada pela Mercado Aberto, a revista interrompia sua regularidade. Assim, a diretoria da ALB se justificava: "Infelizmente [...] um conjunto de circunstâncias 
editoriais, que escapam ao nosso controle, impediram a publicação do número 41 da revista em setembro de 2003, como estava previsto". A carta aos associados também anunciava a nova editora que passaria a ocupar-se da publicação do periódico e sua disposição em torná-la quadrimestral, o que de fato só viria a ocorrer 12 anos depois.

Quando veio à público, a LTP $n^{\circ} 41$ anunciou em seu editorial o fim da parceria com a editora Mercado Aberto, "[...] tradicional e querida companheira de todo um percurso". Os editores da revista despediram-se com palavras carinhosas de uma editora que durante 21 anos, "[...] de modo intenso e qualificado, ajudou-nos a ampliar o debate a respeito da democratização da leitura e acesso à escrita”, não apenas gerando os primeiros 42 números da revista $\left(\right.$ do $^{\circ} \mathrm{O}$ ao $\left.\mathrm{n}^{\circ} 41\right)$ como fazendo parceria em outras publicações e ações da ALB ao longo desse tempo. Registram seu agradecimento, apresentam a nova parceira, a Editora Global, de São Paulo, e manifestam o desejo de "ajustar a revista conforme os padrões de qualidade presentes em revistas dessa natureza." (LTP, $\mathrm{n}^{\circ} 41,2003$, Editorial).

O número seguinte (LTP, $\mathrm{n}^{\circ}$ 42, 2004) já traz um novo visual no layout de capa e no miolo, novas diagramação e encadernação. De uma encadernação em forma de brochura, passa a ser colada e com lombada. Se até então as imagens centrais da capa eram enquadradas, a partir de agora ocupam toda a extensão da capa. $\mathrm{O}$ cabeçalho, que se manteve inalterado por 41 números sofre também pequenas alterações. Num editorial, que era uma carta aos sócios, assinantes e colaboradores, foram apresentadas as mudanças na estrutura até então vigente, e que começam a se materializar naquele número:

Este número da revista Leitura: teoria e prática pretende consolidar a nova parceria com a editora Global e anunciar as mudanças desejadas com o intuito de dar "uma nova cara" à nossa publicação. Esta nova configuração está sendo organizada com a permanência de algumas seções já familiares ao nosso público leitor, como: Editorial, Estudos/Artigos, Relato de experiências, Textos Literários, Imagens de Leitura e com a inclusão de outras que vem para atender novos anseios da equipe editorial e de nossos leitores. [...] Mudanças significativas ficarão por conta da "invenção" de novas seç̃oes: Textos provocativos/líricos; Palavra da ALB; Seção de cartas/Seção do leitor [...] (LTP, $\mathrm{n}^{\mathrm{o}} 42,2004$, Editorial)

11. Carta aos associados, de 19 de junho de 2004, assinada pelo Presidente da diretoria da ALB, Luís Percival Leme de Britto, e que acompanhava a remessa pelo correio da revista $\mathrm{n}^{\circ} 41$. 
O texto encerra-se com um convite aos leitores para que se manifestem, convertendo-se em interlocutores da revista, um expediente já utilizado de maneira reiterada anteriormente e que reforça não apenas o aspecto inclusivo da revista, como também o fato de que suas escolhas, linha editorial e qualidade precisam ser atestadas ou questionadas pelos leitores, seus reais destinatários:

[...] a participação crítica de todos os leitores é muito importante. Eles certamente poderão nos ajudar, enviando sugestões para enriquecer a proposta (LTP, no o, 1983, Editorial).

[...] encarecemos aos associados da ALB e demais leitores que enviem avaliações constantes de 'Leitura: Teoria \& Prática', em todos os seus aspectos (conteúdo, composição gráfica, ilustração, diagramação, distribuição, etc.) (LTP, no 01, 1983, Editorial).

Um pedido aos nossos leitores: escrever cartas à redação de 'Leitura: Teoria \& Prática' sobre os textos publicados e a revista em geral de modo que possamos iniciar uma nova seção. Dessa forma, os autores dos artigos poderão obter um feedback sobre aquilo que refletiram, inaugurando um excelente espaço de conversa. Que venham as cartas! (LTP, no ${ }^{\circ}$, 1990, Editorial)

E se os leitores, através de e-mails ou cartas nos ajudarem a construir um outro desenho para Leitura: Teoria \& Prática nos próximos anos? (LTP, nº 41, 2003, Editorial)

No mais, continuamos à espera de que vocês se manifestem, tornando-se nossos interlocutores de fato, para que possamos melhorar nossa publicação e ampliar nosso rol de leitores e colaboradores. (LTP, $\mathrm{n}^{\circ} 42,2004$, Editorial).

A parceria com a editora Global foi até novembro de 2012, durando nove anos, gerando 11 números da LTP (do ${ }^{\circ}{ }^{\circ}$ 2, de março de 2004 ao $n^{\circ} 58$, de junho de 2012). Essa editora foi também parceira da ALB em coleções de livros, nos congressos de leitura etc.

Se, como vimos acima, as escolhas da revista, durante muito tempo, dependeram prioritariamente das avaliações do Conselho Editorial e de sua comunidade de leitores, nesse momento a revista inicia uma resposta, de forma mais objetiva e 
acentuada, às exigências trazidas pela CAPES (Coordenação de Aperfeiçoamento de Pessoal de Nível Superior) no que diz respeito à qualificação dos periódicos especializados. Foi nesse período que houve a inserção de um artigo internacional (agora obrigatório) em uma seção própria ou não, muito embora desde algum tempo ele estivesse, vez ou outra, presente na revista. Também foi nesse momento que se passou a informar, ao final de cada texto publicado, a data de seu recebimento e aceite para publicação; a buscar maior representatividade das diversas regiões do país, tanto para seleção de pareceristas dos textos como para autores publicados; a exigir resumo e abstract para todos os artigos; a publicar os dossiês, ao menos uma vez ao ano, reunindo autores de instituições diferentes em torno de um tema comum; a divulgar as normas para publicação. A revista, em seus números 58 e 59 teve o apoio financeiro da Capes e CNPq. 

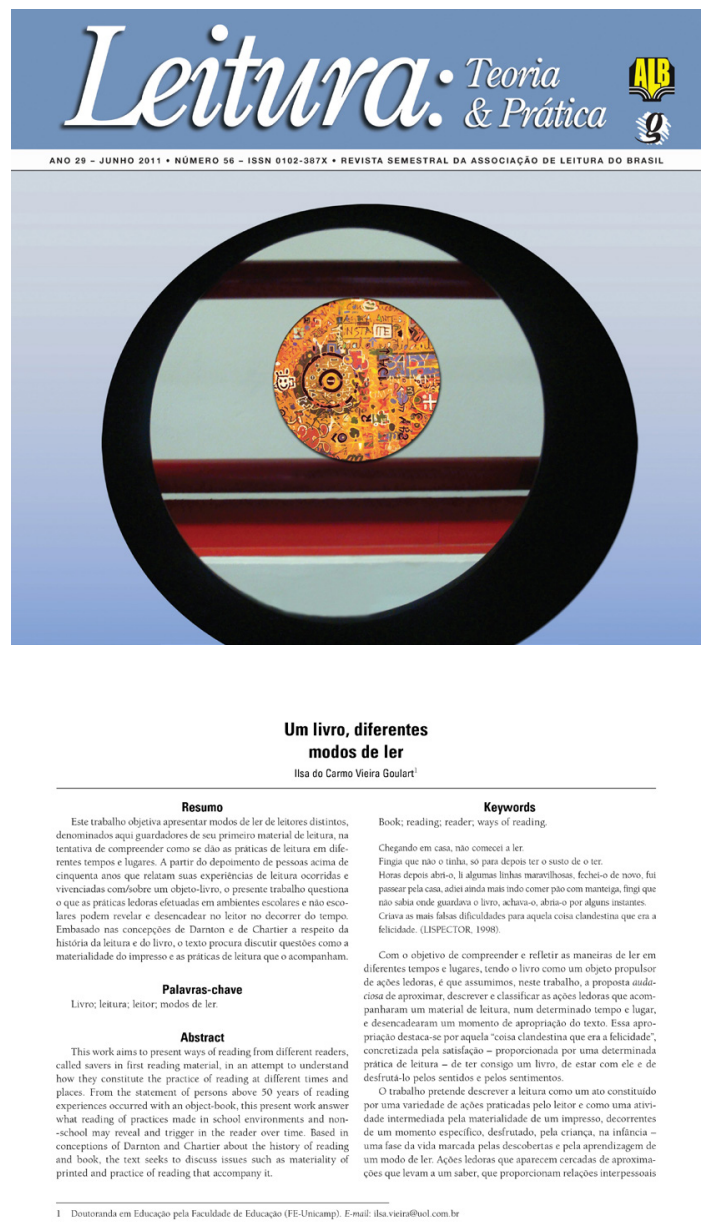

27

Figuras o5 e 06: Revista Leitura: Teoria \& Prática, n5 56, 2011. Capa e p. 27

IV

Nesse percurso, houve ainda momentos especiais da revista Leitura: Teoria \& Prática. A celebração de seus 25 anos, durante o $16^{\circ}$ Cole, em 2007, contou com o lançamento de um CD-ROM contendo os dez primeiros números da revista e uma exposição das capas de todos os números já publicados, no Ginásio Multidisciplinar da Unicamp. 

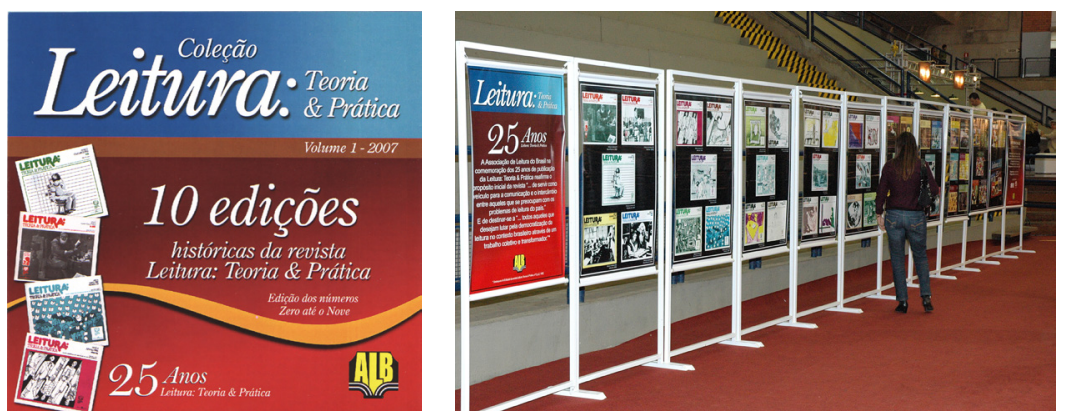

Figuras 07 e 08: 25 Anos da Revista Leitura: Teoria \& Prática, CD-Rom Comemorativo e foto da Exposição, 2007

No $18^{\circ}$ Congresso de Leitura do Brasil, em 2012, foram produzidas duas edições da LTP, uma foi em CD: um suplemento para publicar os textos do $18^{\circ}$ Cole. Em outubro do mesmo ano, houve também um número especial para homenagear o Prof. Dr. Milton José de Almeida ${ }^{12}$, um colaborador importante da LTP, docente da Faculdade de Educação da Unicamp, que atuou na LTP em seu Conselho Editorial, com artigos, textos de ficção e como capista em muitos números. ${ }^{13}$

12. O professor Milton faleceu em 2011.

13. A ALB, no $18^{\circ}$ COLE, homenageou o escritor Bartolomeu Campos de Queirós (falecido em 2012), com uma coletânea de textos publicada pela Ed. Moderna e distribuída a todos os participantes do congresso. 


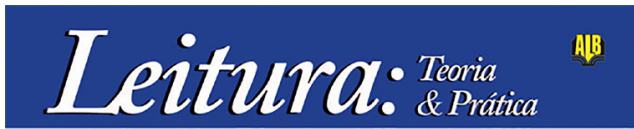

ANO 30 - OUTUBRO 2012 - NUMERO ESPECIAL - ISSN 0102-337X - REVISTA DA ASSOCIAGAO DE LEITURA DO BRASIL

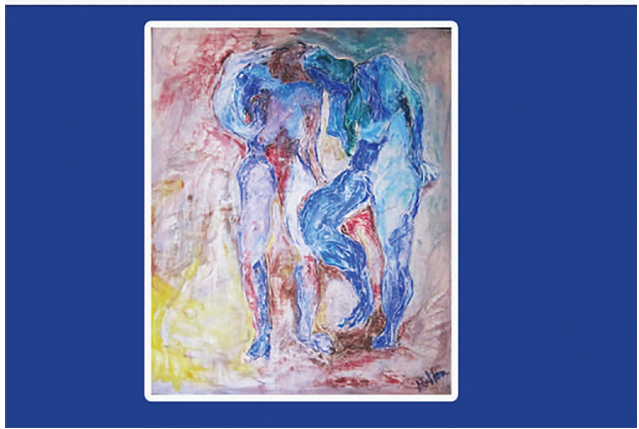

Figura 09: Revista Leitura: Teoria \& Prática, número especial, 2012, em homenagem ao Prof. Milton José de Almeida.

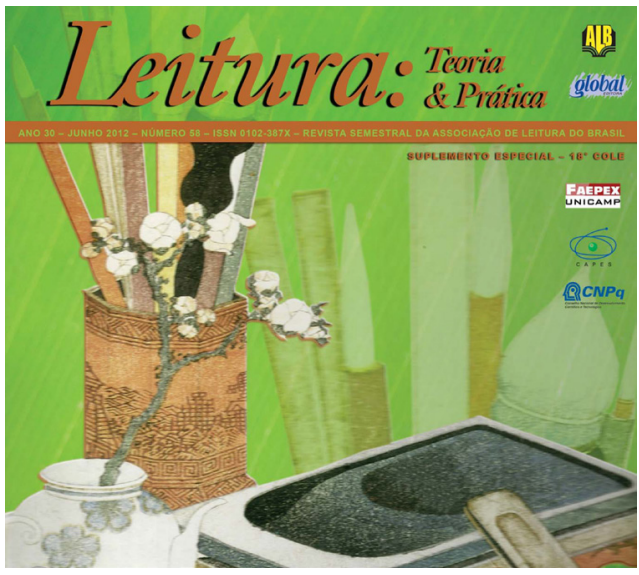

Figura 10: Suplemento especial da LTP, com textos do $18^{\circ}$ COLE, publicado em CD-ROM em 2012.

Quando a LTP passou a ser confeccionada, em junho de 2013, pela editora do Sesi-SP, produziu-se importante alteração em seu formato e diagramação do texto na página. Sua dimensão passou a ser de $18 \mathrm{~cm}$ x $25 \mathrm{~cm}$, deixando-a mais próxima do 
livro convencional, e o texto começou a ocupar a página em um único bloco. Vários elementos de layout sofreram alterações, assim como a capa e o miolo. A revista praticamente dobrou o número de páginas.

O editorial do número 6o, além de anunciar mais essa nova parceria e o novo visual do periódico, registra o fato de que o processo de submissão e avaliação de textos da LTP passaria a ser feito pelo Sistema Eletrônico de Editoração de Revistas (SEER) e que ela estaria disponível, em versão digital e gratuita, no site da revista (https://ltp.emnuvens.com.br/ltp). ${ }^{14}$ Esclarece também que, desde 2010, a ALB colocava LTP em versão digital no site da entidade apenas para os associados, que a acessavam com senha e login ( ${ }^{\circ} 54$ ao 59 ), e que a partir de dezembro de 2012 a revista passou a ter acesso irrestrito e gratuito, sendo que aos associados em dia seguia também a versão impressa.

A parceria com a editora do Sesi não foi longa, rendendo apenas quatro números da LTP (do no 6o, de junho de 2013 ao no63, de dezembro de 2014). Desde então, a LTP vem sendo publicada pela própria ALB, que arca com os custos de revisão, editoração, impressão e disponibilização na Internet. Manteve-se, entretanto, o mesmo formato, projeto gráfico e linha editorial.

Lendo os editoriais dos últimos números da revista (do $n^{\circ} 60$ ao 69), encontramos palavras que sinalizam ênfases da revista no período: plural, múltiplos, invenção, criação, imaginação, partilha, coletivo, conexão, redes, experimentações, intercultural, atravessamentos.... Essas palavras habitam expressões e ajudam a dar força a modos de pensar. Delas é feito um uso recorrente e podemos atribuir o sentido de que a revista, com isso, afirma seu caráter de abertura, dado o amplo escopo da expressão leitura. Da mesma forma, a revista falará das diferentes possibilidades em abordagens da leitura pelos distintos campos do conhecimento.

Em nome da Diretoria da Associação de Leitura do Brasil (ALB) pensando a leitura em seus sentidos mais plurais, atravessados pelas artes, pelas experimentações... (LTP, no 63, 2014, p. 08 ).

14. Nos primeiros 40 números da LTP, não eram publicadas quaisquer diretrizes para os autores. A partir do $\mathrm{n}^{\circ} 41$ aparece nas últimas páginas um conjunto de normas, solicitando, entre outras coisas, que as colaborações sejam enviadas à "Editoria da Revista por correio postal em disquete 3,5", CD-ROM, ou via correio eletrônico (secretaria@alb.com.br)” (LTP, no 41, 2003, p. 108). 
Ler tem a ver com abrir-se a esse sem fim de possibilidades de conexões. Esses textos, entendemos, incitam a pensar a leitura e seus atravessamentos, suas potências... (LTP, no 64,2015 , p. 11).

As diferenças expressam-se nas possibilidades analíticas de pensar a leitura... (LTP, no 61,2013, p. 8).

Abertura semelhante à que inaugurou a LTP nos anos 8o. Uma revista que se abria a um outro cuja recepção e cuja voz eram geralmente ausentes das publicações provenientes da academia - o professor. A LTP queria acolher não só sua leitura, mas sua expressão e sua experiência. Abertura com a qual, mais à frente no tempo, se passou a considerar a leitura para além da fronteira escolar, afirmando seu caráter de uma prática não apenas escolar, mas cultural e que atravessa todos os grupos sociais, inclusive aquelas comunidades não escolarizadas e consideradas analfabetas.

Também é pelos editoriais, especialmente dos números 65, 66 e 67, de 2015 e 2016 que fica evidenciado o vínculo forte da revista com o momento histórico de sua produção. Se, em seu início, a LTP esteve marcada pelas lutas da sociedade civil que buscava maior participação política, maior experiência democrática em todos os setores da vida, nesses números, os editoriais mencionam fatos e movimentos contemporâneos que provocam indignação.

Tempos difíceis estes que nos forçam sempre a pensar nosso entorno com o coração apertado. (LTP, no 66, 2016, p. 10).

Em um momento em que as leituras se radicalizam a ponto de promoverem intolerância e descolamento-distanciamento das necessidades do outro... (LTP, no 67, 2016, p. 9).

No ano de 2016, a revista, até então semestral, finalmente ganha mais um número no ano e passa a ser quadrimestral, cumprindo um desejo antigo da entidade, preenchendo, também, mais um quesito da agência avaliadora dos periódicos especializados (Capes) e, ainda, dando maior vazão à publicação dos textos submetidos que no tempo se multiplicaram. O primeiro número de 2017 (LTP, no 68) apresenta um editorial que comunica a disposição da diretoria de disponibilizar mensalmente em formato digital os números da revista que atualmente estão apenas impressos... "Cientes da importância histórica do debate em torno do ato de ler, da construção da 
resistência e da democratização da leitura no nosso país..." (LTP, no 68, 2017, p. 09) e reafirma o compromisso da primeira edição da LTP, de novembro de 1982, explicitado em seu editorial: "[...] servir como veículo para a comunicação e o intercâmbio entre aqueles que se preocupam com os problemas de leitura em nosso país especificamente, a todos aqueles que desejam lutar pela democratização da leitura no contexto brasileiro através de um trabalho coletivo e transformador." (LTP, nº 69, 2017, p. 10).

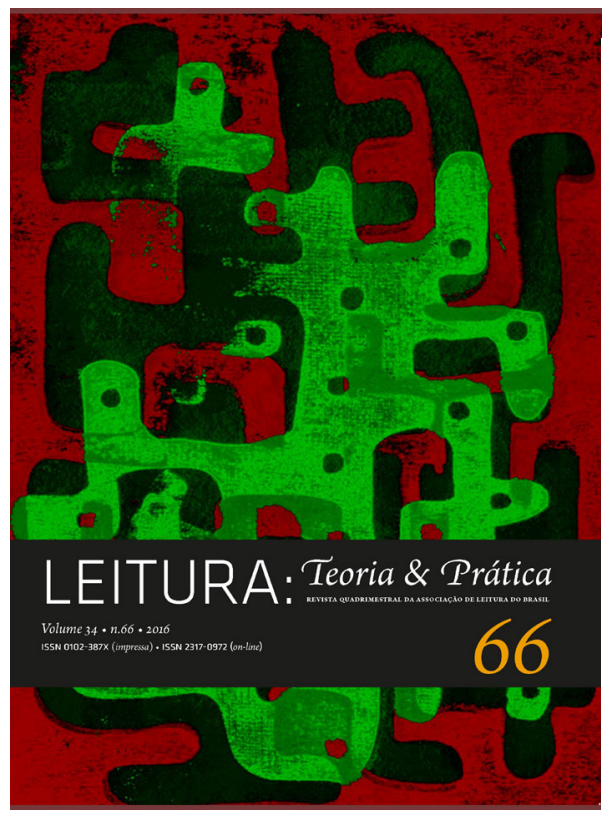

Notas para pensar uma leitura... o aprendizado da vontade criadora de Zaratustra

MARIA DOS REMÉDIOS DE BRITO'

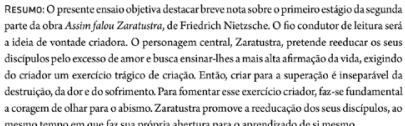

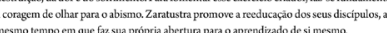
PALAVRAS-CHAVE: Vontade criadora; Zaretustra; discipulos.

ABSTRACT: The article intention is to highlight a note in the first stage of the second part

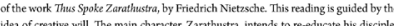

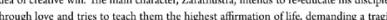
exercise of creation from the creator. Therefore creating for overcoming is inseparable from

Figuras 11 e 12: Revista Leitura: Teoria \& Prática, no 66, 2016. Capa e p. 31

\section{REFERÊNCIAS}

TAKAMATSU, Sonia Midori. 2017. Artes de fazer: memória, participação e história nos 30 anos da Associação de Leitura do Brasil (1978-1985). Tese (Doutorado em Educação)- Faculdade de Educação, Universidade Estadual de Campinas, Campinas, 2017.

SILVA, Lilian Lopes Martin; OLIVEIRA, Luciane Moreira (Org.). Tempo de Cole. Campinas, SP: FE/UNICAMP, 2014.

SILVA, Lilian Lopes Martin. A Revista Leitura: Teoria \& Prática e o professor - um leitor em formação. In: MARINHO, Marildes; SILVA, Ceris Salete Ribas (Org.). Leituras do Professor. Campinas, SP: ALB; Editora Mercado de Letras, 1998. p. 141-156. 
Documentos citados

Carta aos associados da ALB, 19 de junho de 2004.

Leitura: Teoria é Prática. $\mathrm{n}^{\circ}$ o, Campinas, SP: ALB / Porto Alegre, RS: Mercado Aberto, 1983. Leitura: Teoria \& Prática. $\mathrm{n}^{\circ}{ }_{1}$, Campinas, SP: ALB / Porto Alegre, RS: Mercado Aberto, 1983. Leitura: Teoria \& Prática. $\mathrm{n}^{\circ} 10$, Campinas, SP: ALB / Porto Alegre, RS: Mercado Aberto, 1987. Leitura: Teoria \& Prática. $\mathrm{n}^{\circ}$ 15, Campinas, SP: ALB / Porto Alegre, RS: Mercado Aberto, 1990. Leitura: Teoria \& Prática. $\mathrm{n}^{\circ}$ 17, Campinas, SP: ALB / Porto Alegre, RS: Mercado Aberto, 1991. Leitura: Teoria é Prática. $\mathrm{n}^{\circ}$ 23, Campinas, SP: ALB / Porto Alegre, RS: Mercado Aberto, 1994. Leitura: Teoria \& Prática. no 24, Campinas, SP: ALB / Porto Alegre, RS: Mercado Aberto, 1994. Leitura: Teoria \& Prática. no 33 , Campinas, SP: ALB / Porto Alegre, RS: Mercado Aberto, 1999. Leitura: Teoria \& Prática. $\mathrm{n}^{\circ}$ 41, Campinas, SP: ALB / Porto Alegre, RS: Mercado Aberto, 2003. Leitura: Teoria \& Prática. no ${ }^{\circ}$ 2, Campinas, SP: ALB / São Paulo, SP: Global Editora, 2004. Leitura: Teoria \& Prática. no 56 , Campinas, SP: ALB / São Paulo, SP: Global Editora, 2011. Leitura: Teoria \& Prática. no 58 , Campinas, SP: ALB / São Paulo, SP: Global Editora, 2012. Leitura: Teoria \& Prática. no 59, Campinas, SP: ALB / São Paulo, SP: Global Editora, 2012. Leitura: Teoria \& Prática. Edição especial, Campinas, SP: ALB, 2012.

Leitura: Teoria \& Prática. Edição especial (CD-ROM), Campinas, SP: ALB, 2012.

Leitura: Teoria \& Prática. no 60, Campinas, SP: ALB / São Paulo, SP: SESI-Editora, 2013. Leitura: Teoria \& ' Prática. no 61, Campinas, SP: ALB / São Paulo, SP: SESI-Editora, 2013. Leitura: Teoria \& Prática. $\mathrm{n}^{\circ}$ 62, Campinas, SP: ALB / São Paulo, SP: SESI-Editora, 2014. Leitura: Teoria \& Prática. no 63, Campinas, SP: ALB / São Paulo, SP: SESI-Editora, 2014. Leitura: Teoria \& Prática. no 64, Campinas, SP: ALB, 2015. Leitura: Teoria e̛ Prática. $\mathrm{n}^{\circ}$ 65, Campinas, SP: ALB, 2015. Leitura: Teoria \& Prática. no 66, Campinas, SP: ALB, 2016. Leitura: Teoria é Prática. no 67, Campinas, SP: ALB, 2016. Leitura: Teoria é Prática. $\mathrm{n}^{\circ}$ 68, Campinas, SP: ALB, 2016. Leitura: Teoria \& Prática. n 69 , Campinas, SP: ALB, 2017.

\section{SOBRe OS AUTORES}

Lilian Lopes Martin da Silva é graduada em Linguística (Universidade Estadual de Campinas), tem Mestrado e Doutorado em Educação (Universidade Estadual de Campinas).É professora colaboradora da Universidade Estadual de Campinas e pesquisadora do Grupo de Pesquisa ALLE/AULA (Alfabetização, Leitura e Escrita/Trabalho Docente na Formação Inicial). Tem experiência na área de educação e leitura, ensino da língua e da literatura, formação de professores, com pesquisa nos seguintes tema: práticas de leitura; biblioteca; história da leitura. E-mail: lilian.lmsilva@gmail.com. 
Ezequiel Theodoro da Silva é graduado em Língua e Literatura Inglesa (Pontifícia Universidade Católica de São Paulo), Mestre em Educação - Leitura (University of Miami) e Doutor em Educação (Pontifícia Universidade Católica de São Paulo). Possui Livre Docência em Metodologia de Ensino (Universidade Estadual de Campinas). Atua como professor visitante junto ao Grupo de Pesquisa ALLE (Alfabetização, Leitura e Escrita) nessa mesma universidade e, em abril de 2015, passou a compor a equipe de professores pesquisadores do programa de Mestrado Interdisciplinar Stricto Sensu em Desenvolvimento e Sociedade da Universidade Alto Vale do Rio do Peixe (UNIARP). Em janeiro de 2016 assumiu a coordenação do Mestrado Profissional em Educação Básica dessa instituição. Comanda os trabalhos da Editora Leitura Crítica e o Portal Leitura Crítica, onde inseriu boa parte da sua obra e promove a formação continuada e a atualização dos professores brasileiros para o ensino da leitura.

E-mail:emarthi@outlook.com.br.

Luciane Moreira de Oliveira é graduada em Pedagogia (Universidade Estadual de Campinas), e tem especialização em Administração da Cultura (Fundação Getúlio Vargas), Mestrado em Educação (Universidade Estadual de Campinas) e mestrado profissional em Museologia (Universidad de Valladolid, Espanha). É pesquisadora do Grupo de Pesquisa ALLE/AULA (Alfabetização, Leitura e Escrita/Trabalho Docente na Formação Inicial). Tem experiência e atuação nas áreas de educação, formação de professores, cultura, artes e museologia. Atualmente pesquisa os seguintes temas: história da leitura, leitor, imprensa ilustrada, editor e leitura.

E-mail: luciane.oliveira.br@gmail.com.

Recebido em 03 de setembro de 2017 e aprovado em o8 de setembro de 2017. 